\title{
Factors controlling the dynamics of the B chromosome polymorphism in Korean rye
}

\author{
F. ROMERA, M. M. JIMENEZ \& M. J. PUERTAS \\ Departamento de Genetica, Facultad de Biologia, Universidad Complutense, 28040 Madrid, Spain
}

\begin{abstract}
In order to test if a particular rye population has a specific frequency of B chromosomes or, on the contrary, if it can tolerate Bs over a wide range of frequencies, we have studied the transmission of Bs in two Korean varieties which differ in their natural B frequencies. Synthetic populations were made for each variety which carried Bs at both the natural frequency as well as at the frequency of the alternative population. The populations were open pollinated, and the frequencies of the Bs were studied over three generations. The experiment was duplicated in two different environments and the variables of viability and fertility were also compared.

Fertility was lower in the $2 \mathrm{~B}$ than in the $0 \mathrm{~B}$ plants, and it was much lower again in the $4 \mathrm{~B}$ ones. Viability was not dependent on the number of Bs. The results were similar for both environments and this finding argues against an adaptive role for B chromosomes.

The frequency of Bs in the populations sown at their natural frequencies remained constant over the generations in both environments, while the Bs of both varieties tended to move towards their natural frequencies after they were experimentally changed.

There was a strong tendency for the proportion of plants with Bs in the variety with a high natural frequency to increase, while the tendency for the proportion of plants with Bs in the variety with a low natural frequency to decrease was less. These results indicate just how strong are the forces which maintain Bs in populations in the face of their harmful effects upon fertility.

In our opinion the genes that control B transmission rates are the main factors that determine the range of frequencies at which a natural population can carry $\mathrm{B}$ chromosomes, while the tendency to recover natural frequencies rapidly following a disturbance is due to frequency-dependent selection and to a maternal imprinting effect.
\end{abstract}

Keywords: B chromosomes; Secale cereale.

\section{Introduction}

B chromosomes exist at different frequencies in different populations of rye. The highest frequencies of plants wth Bs are found in populations from Japan (Kishikawa, 1965) and Korea (Müntzing, 1954, 1957a,b; Lee, 1963, 1966, 1976, 1981; Lee \& Min, $1965,1966,1968)$. These authors reported a wide variation in B chromosome frequencies among Korean populations which was unrelated to any geographic or ecological cline.

It has been repeatedly argued by many authors that the polymorphism for $\mathrm{B}$ chromosomes is maintained by a balance between their tendency to increase in number due to their non-Mendelian accumulation mechanisms, and the decrease in fertility of individuals with a high number of Bs (Jones \& Rees, 1982 for a review).

However, in a recent paper (Romera et al., 1989) we reported a quantitative analysis of these two opposing factors in four Korean populations with different frequencies of $\mathrm{Bs}$, where we found that both the behaviour of $\mathrm{B}$ chromosomes during male gametogenesis and the decrease in fertility were similar in all populations. We therefore concluded that the balance between these two factors cannot account for the establishment of equilibria at different frequencies in different populations, although these features are essential for the existence of the polymorphism for B chromosomes within a population.

It is possible however that B chromosomes could be maintained at a wide range of frequencies provided that 
the tendency for B loss due to instabilities at meiosis, and the low fitness of plants carrying a high number of Bs, was compensated by a sufficient proportion of gametes carrying Bs formed in each generation by the accumulation mechanisms.

In order to test if a particular population has a specific frequency of $\mathrm{B}$ chromosomes or, on the contrary, it can tolerate Bs at a wide range of frequencies, we have designed the present experiment. The idea was to study the transmission of Bs in two different varieties, which show a high and low B frequency in nature, and to derive synthetic populations with both the natural and the opposite $\mathrm{B}$ frequencies. The populations were open pollinated, and the frequency of Bs was studied over three generations. We first wanted to see whether or not the populations conserved their natural frequencies, and secondly if they moved towards their natural frequencies after having been experimentally changed.

The experiment was duplicated in two different environments in which the variables of viability and fertility were also compared.

\section{Materials and methods}

Two Korean varieties of Secale cereale were used: Paldang, with a low natural frequency of plants with B chromosomes (20 per cent), and Puyo with a high natural frequency ( 60 per cent). The seeds were collected from natural populations and were kindly supplied by Dr Lee from the Seoul National University.

A large number of plants were screened for their B number from each variety at the seedling stage. Four synthetic populations were then made of about 70 plants each, two with the natural frequencies (Paldang 20 and Puyo 60) and two with the opposite frequencies (Paldang 60 and Puyo 20). The seedlings were planted in plots in an experimental field, with the exact number of plants corresponding to the frequencies of plants with $\mathrm{Bs}$ and with the mean number of Bs per plant observed in the natural varieties. Several plants subsequently died, and the numbers that survived to maturity are shown in Table 2. Using these frequencies, which differ only slightly from natural ones, we started the experiment in Madrid in 1987, and the plants were allowed to open pollinate over two more generations during 1988 and 1989. A sample of the seed obtained every year was screened for the presence of B chromosomes.

The experiment was duplicated in two experimental fields located in Madrid and also in La Coruna, which has a different climate. Madrid is situated in the centre of Spain at $700 \mathrm{~m}$ above sea level. It has a Mediterranean-continental climate, with a low mean rainfall.
Conversely, La Coruña is situated in the north-west of Spain, $5 \mathrm{~m}$ above sea level. It has a humid and moderate Atlantic climate, due to the direct influence of a marine wind. The mean annual rainfall is about $1000 \mathrm{~mm}$.

At anthesis the plants in each plot were covered with a cotton fabric to prevent cross-pollination among the plots but allowing open pollination within them. The offspring were screened for the presence of B chromosomes and a random sample was then planted to obtain the next generation.

The plots were also planted in La Coruña in 1987 but the experiment failed due to causes beyond our control. We therefore prepared new plots for planting in La Coruña in 1988. To prepare a Paldang 60 population it is necessary to screen a large number of seedlings because 4B plants are rarely found in Paldang, and the same is true for Puyo 20 as sufficient $0 \mathrm{~B}$ plants are not easy to find. We therefore prepared Paldang 60 and Puyo 20 for La Coruña in 1988, not from the natural varieties, but from the Paldang 60 and Puyo 20 experimental populations obtained in Madrid the year before. This arrangement has probably influenced the results, as we will discuss later.

The progeny plants were collected individually in order to count the number of spikes, flowers and grains per plant, and from these data variables which affect viability and fertility were estimated. For each population the mean number of flowers per plant $(\mathrm{F} / \mathrm{P})$, flowers per spike $(F / S)$, spikes per plant $(S / P)$, grains per plant $(G / P)$, grains per spike $(G / S)$ and grains per flower $(\mathrm{G} / \mathrm{F})$ was estimated.

In all cases the chromosome number was counted in root tips following fixation in acetic alcohol $1: 3$ and staining by the Feulgen method.

\section{Results}

In 1987 a large number of seeds from the varieties Paldang and Puyo were screened for the presence of B chromosomes at the seedling stage. The results of this screening are shown in Table 1. Paldang showed 20 per cent of plants with Bs and Puyo 60 per cent, which we consider to be the natural $\mathrm{B}$ frequencies for these varieties.

Table 2 shows the frequency of B chromosomes in the eight experimental populations, over three generations in Madrid (1987-1988-1989) and two in La Coruña (1988-1989).

Table 3 shows the results of the chi-squared contingency tests made to compare the number of plants with and without Bs between the generations. It is evident that the experimental populations planted with the synthetic natural frequencies of $\mathrm{B}$ chromosomes 
Table 1 Frequency of B chromosomes in the Korean rye varieties Paldang and Puyo

Number of Bs

\begin{tabular}{llllllllll} 
Population & 0 & 1 & 2 & 3 & 4 & 6 & TP & PB & B/P \\
\hline Paldang & 501 & & 119 & 1 & 5 & & 626 & 0.20 & 0.42 \\
Puyo & 259 & 12 & 255 & 2 & 78 & 21 & 627 & 0.59 & 1.54
\end{tabular}

$\mathrm{TP}=$ Total number of plants screened.

$\mathrm{PB}=$ Frequency of plants with $\mathrm{Bs}$.

$\mathrm{B} / \mathrm{P}=$ Mean number of $\mathrm{Bs}$ per plant.

Table 2 Frequency of B chromosomes in experimental populations of Paldang and Puyo rye, growing in Madrid and in La Coruña, over three or two generations

\begin{tabular}{|c|c|c|c|c|c|c|c|c|c|}
\hline \multirow[b]{2}{*}{ Population } & \multirow[b]{2}{*}{ Year } & \multicolumn{5}{|c|}{ Number of Bs } & \multirow[b]{2}{*}{ TP } & \multirow[b]{2}{*}{ PB } & \multirow[b]{2}{*}{$\mathrm{B} / \mathrm{P}$} \\
\hline & & 0 & 1 & 2 & 3 & 46 & & & \\
\hline aldang 20 & 1987 & 55 & & 11 & & & 66 & 0.17 & 0.33 \\
\hline Madrid & $\begin{array}{l}1988 \\
1989\end{array}$ & $\begin{array}{l}79 \\
80\end{array}$ & 2 & $\begin{array}{l}21 \\
17\end{array}$ & & 1 & $\begin{array}{l}100 \\
100\end{array}$ & $\begin{array}{l}0.21 \\
0.20\end{array}$ & $\begin{array}{l}0.42 \\
0.40\end{array}$ \\
\hline $\begin{array}{l}\text { Paldang } 60 \\
\text { Madrid }\end{array}$ & $\begin{array}{l}1987 \\
1988 \\
1989\end{array}$ & $\begin{array}{r}32 \\
159 \\
62\end{array}$ & $\begin{array}{l}6 \\
1\end{array}$ & $\begin{array}{r}35 \\
101 \\
32\end{array}$ & $\begin{array}{l}1 \\
1\end{array}$ & $\begin{array}{l}4 \\
9 \\
4\end{array}$ & $\begin{array}{r}71 \\
276 \\
100\end{array}$ & $\begin{array}{l}0.55 \\
0.42 \\
0.38\end{array}$ & $\begin{array}{l}1.21 \\
0.89 \\
0.82\end{array}$ \\
\hline & $\begin{array}{l}1987 \\
1988 \\
1989\end{array}$ & $\begin{array}{r}56 \\
161 \\
43\end{array}$ & $\begin{array}{l}6 \\
5\end{array}$ & $\begin{array}{r}16 \\
129 \\
41\end{array}$ & $\begin{array}{ll}1 & \\
1 & 1\end{array}$ & $\begin{array}{l}8 \\
0\end{array}$ & $\begin{array}{r}72 \\
305 \\
100\end{array}$ & $\begin{array}{l}0.22 \\
0.47 \\
0.57\end{array}$ & $\begin{array}{l}0.44 \\
0.98 \\
1.30\end{array}$ \\
\hline & $\begin{array}{l}1987 \\
1988 \\
1989\end{array}$ & $\begin{array}{l}31 \\
29 \\
26\end{array}$ & $\begin{array}{r}3 \\
12\end{array}$ & $\begin{array}{l}33 \\
48 \\
45\end{array}$ & $\begin{array}{ll}2 & 1 \\
& 1\end{array}$ & $\begin{array}{ll}8 & \\
6 & 2 \\
5 & 2\end{array}$ & $\begin{array}{r}72 \\
100 \\
100\end{array}$ & $\begin{array}{l}0.57 \\
0.71 \\
0.74\end{array}$ & $\begin{array}{l}1.36 \\
1.78 \\
1.74\end{array}$ \\
\hline & $\begin{array}{l}1988 \\
1989\end{array}$ & $\begin{array}{l}56 \\
61\end{array}$ & 2 & 23 & & 2 & $\begin{array}{l}72 \\
88\end{array}$ & $\begin{array}{l}0.22 \\
0.30\end{array}$ & $\begin{array}{l}0.44 \\
0.63\end{array}$ \\
\hline $\begin{array}{l}\text { Paldang } 60 \\
\text { La Coruña }\end{array}$ & $\begin{array}{l}1988 \\
1989\end{array}$ & $\begin{array}{l}27 \\
53\end{array}$ & 4 & $\begin{array}{l}31 \\
37\end{array}$ & & $\begin{array}{l}1 \\
6\end{array}$ & $\begin{array}{r}59 \\
100\end{array}$ & $\begin{array}{l}0.54 \\
0.47\end{array}$ & $\begin{array}{l}1.19 \\
1.02\end{array}$ \\
\hline $\begin{array}{l}\text { Puyo } 20 \\
\text { La Coruña }\end{array}$ & $\begin{array}{l}1988 \\
1989\end{array}$ & $\begin{array}{l}59 \\
63\end{array}$ & 2 & $\begin{array}{l}14 \\
27\end{array}$ & & 8 & $\begin{array}{r}72 \\
100\end{array}$ & $\begin{array}{l}0.19 \\
0.34\end{array}$ & $\begin{array}{l}0.39 \\
0.66\end{array}$ \\
\hline La Coruña & $\begin{array}{l}1988 \\
1989\end{array}$ & $\begin{array}{l}34 \\
50\end{array}$ & 6 & $\begin{array}{l}33 \\
39\end{array}$ & & $\begin{array}{l}4 \\
5\end{array}$ & $\begin{array}{r}71 \\
100\end{array}$ & $\begin{array}{l}0.52 \\
0.50\end{array}$ & $\begin{array}{l}1.15 \\
1.04\end{array}$ \\
\hline
\end{tabular}

$\mathrm{TP}=$ Total number of plants screened.

$\mathrm{PB}=$ Frequency of plants with $\mathrm{Bs}$.

$\mathrm{B} / \mathrm{P}=$ Mean number of $\mathrm{Bs}$ per plant.

maintain these frequencies, both in Madrid and in La Coruna, while the populations sown with the synthetic opposite frequencies tend to shift towards their natural ones, especially in Madrid.

The number of flowers, spikes and grains per plant was counted in 1988 in Madrid and in 1989 in La Coruña. The mean values of the variables which affect
Table 3 Results of chi-squared contingency tests between plants with and without $B s$ in the experimental populations of Paldang and Puyo growing in Madrid and in La Coruna

\begin{tabular}{clllll}
\hline & \multicolumn{3}{l}{$\begin{array}{l}\text { Natural frequencies } \\
\text { Madrid }\end{array}$} & & \multicolumn{2}{l}{ Switched frequencies } \\
\cline { 2 - 3 } \cline { 5 - 6 } Generation & Paldang 20 & Puyo 60 & & Paldang 60 & Puyo 20 \\
\hline $87-88$ & $\mathrm{~ns}$ & $\mathrm{~ns}$ & & $\mathrm{~ns}$ & $* * *$ \\
$88-89$ & $\mathrm{~ns}$ & $\mathrm{~ns}$ & & $\mathrm{~ns}$ & $* * *$ \\
$87-89$ & $\mathrm{~ns}$ & $\mathrm{~ns}$ & & $*$ & $* * *$ \\
$87-88-89$ & $\mathrm{~ns}$ & $\mathrm{~ns}$ & & $*$ & $* * *$ \\
La Coruña & & & & & \\
$88-89$ & $\mathrm{~ns}$ & $\mathrm{~ns}$ & $\mathrm{~ns}$ & $*$ \\
\hline
\end{tabular}

ns $=$ non-significant, ${ }^{*}$ significant at 0.05 level, ${ }^{* * *}$ significant at 0.001 level.

viability and fertility were estimated, and the results are shown in Table 4 . As we already knew that B chromosomes decrease fertility in Paldang and Puyo in Madrid (Romera et al., 1989), two-way ANOVAS were made to see whether Bs had any differential influence on fertility in the two localities. The results of the ANOVAS are shown in Table 5, where it can be seen that the interaction between locality and B number is not significant for Puyo for all variables, and significant for Paldang for only grains per spike and grains per flower. In Tables 4 and 5 the data of Paldang 20 in La Coruña are not included because the plants could not be individually collected; so the seed was used to screen for the B number but it could not be used to estimate the variables of viability and fertility.

Table 6 shows the quotients for the mean values of $\mathrm{F} / \mathrm{P}, \mathrm{F} / \mathrm{S}, \mathrm{S} / \mathrm{P}, \mathrm{G} / \mathrm{P}, \mathrm{G} / \mathrm{S}$ and $\mathrm{G} / \mathrm{F}$ in $2 \mathrm{~B}$ plants divided by those of $0 \mathrm{~B}$ plants, and the values of $4 \mathrm{~B}$ plants divided by $0 \mathrm{~B}$ ones. These quotients are less than 1 for the values of fertility in all cases, with the quotients 4B/ $0 \mathrm{~B}$ being remarkably low. The quotients for the mean values of viability are generally close to 1 , or higher.

\section{Discussion}

The frequency of B chromosomes in the experimental populations sown at their natural frequencies remains constant over generations both in Madrid and in $\mathrm{La}$ Coruña (Tables 2 and 3). The proportion of Puyo plants with Bs in Madrid tends to increase but the difference is non-significant. This indicates that the polymorphism is stable both in Paldang and Puyo. It can thus be considered that the natural frequency of $B$ chromosomes in Paldang is low, of the order of about 
Table 4 Variables of viability and fertility in the experimental populations

\begin{tabular}{|c|c|c|c|c|c|c|c|c|}
\hline & $\begin{array}{l}\text { Number of } \\
\text { Bs }\end{array}$ & $\begin{array}{l}\text { Number of } \\
\text { plants }\end{array}$ & $\mathrm{F} / \mathrm{P}$ & $\mathrm{F} / \mathrm{S}$ & $\mathrm{S} / \mathrm{P}$ & $\mathrm{G} / \mathrm{P}$ & $\mathrm{G} / \mathrm{S}$ & $\mathrm{G} / \mathrm{F}$ \\
\hline Puyo 20 & 0 & 58 & $477.66 \pm 31.71$ & $66.99 \pm 1.12$ & $7.17 \pm 0.46$ & $164.21 \pm 15.46$ & $24.71 \pm 2.03$ & $0.36 \pm 0.03$ \\
\hline La Coruña & 2 & 14 & $531.29 \pm 76.50$ & $65.44 \pm 2.53$ & $8.07 \pm 1.11$ & $150.93 \pm 33.69$ & $19.38 \pm 3.12$ & $0.29 \pm 0.05$ \\
\hline Puyo 60 & 0 & 34 & $396.18 \pm 31.40$ & $80.45 \pm 2.06$ & $4.94 \pm 0.38$ & $219.88 \pm 21.11$ & $44.75 \pm 2.68$ & $0.56 \pm 0.03$ \\
\hline \multirow[t]{2}{*}{ La Coruña } & 2 & 33 & $406.36 \pm 39.78$ & $78.80 \pm 1.76$ & $5.03 \pm 0.40$ & $200.82 \pm 20.04$ & 39.71 & $0.51 \pm 0.03$ \\
\hline & 4 & 4 & $247.50 \pm 51.86$ & $69.33 \pm 7.70$ & $3.50 \pm 0.62$ & $29.50 \pm 10.49$ & $8.29 \pm 2.88$ & $0.12 \pm 0.04$ \\
\hline Paldang 60 & 0 & 27 & $232.59 \pm 30.61$ & $75.92 \pm 3.14$ & $3.11 \pm 0.42$ & $124.00 \pm 15.98$ & $44.87 \pm 4.00$ & $0.58 \pm 0.04$ \\
\hline \multirow[t]{2}{*}{ La Coruña } & 2 & 31 & $217.42 \pm 25.13$ & $75.30 \pm 1.90$ & $2.90 \pm 0.33$ & 85.06 & 32.60 & $0.43 \pm$ \\
\hline & 4 & 1 & 280 & 70 & 4 & 20 & 5 & 0.32 \\
\hline Puyo 20 & 0 & 56 & 455. & 94.48 & $4.75 \pm 0.37$ & 158.4 & $32.98 \pm 2.44$ & 0.35 \\
\hline Madrid & 2 & 16 & $502.50 \pm 53.34$ & $96.33 \pm 2.79$ & $5.38 \pm 0.71$ & $140.81 \pm 16.68$ & $29.01 \pm 3.42$ & $0.30 \pm 0.03$ \\
\hline Puyo 60 & 0 & 31 & $284.77 \pm 33.64$ & $91.99 \pm 2.19$ & $3.00 \pm 0.32$ & $111.71 \pm 13.93$ & $36.25 \pm 2.19$ & $0.39 \pm 0.02$ \\
\hline \multirow[t]{2}{*}{ Madrid } & 2 & 33 & $311.82 \pm 28.04$ & $99.56 \pm 1.71$ & $3.09 \pm 0.27$ & $95.15 \pm 10.50$ & $31.47 \pm$ & $0.31 \pm 0.02$ \\
\hline & 4 & 8 & $388.00 \pm 123.1$ & $95.75 \pm 34.6$ & $3.88 \pm 1.06$ & $39.13 \pm 10.70$ & $11.77 \pm 2.54$ & $0.12 \pm 0.02$ \\
\hline Paldang 20 & 0 & 55 & $255.64 \pm 18.94$ & $86.86 \pm 1.50$ & $2.91 \pm 0.20$ & $94.40 \pm 7.89$ & $34.10 \pm 2.06$ & $0.39 \pm 0.02$ \\
\hline Madrid & 2 & 11 & $205.45 \pm 58.19$ & $74.57 \pm 6.61$ & $2.55 \pm 0$ & $44.09 \pm 16.31$ & $17.09 \pm 3.77$ & $0.23 \pm 0.05$ \\
\hline Paldang 60 & 0 & 32 & $258.31 \pm 22.12$ & $88.03 \pm 2.59$ & $2.91 \pm 0.21$ & $109.88 \pm 12.04$ & $38.18 \pm 3.27$ & $0.43 \pm 0.03$ \\
\hline \multirow[t]{2}{*}{ Madrid } & 2 & 35 & $240.51 \pm 28.39$ & $80.10 \pm 2.38$ & $2.94 \pm 0.04$ & $81.14 \pm 11.99$ & $27.00 \pm 2.26$ & $0.35 \pm 0.03$ \\
\hline & 4 & 4 & $112.50 \pm 59.50$ & $64.18 \pm 12.5$ & $1.50 \pm 0.05$ & $9.25 \pm 4.84$ & $5.42 \pm 1.72$ & $0.09 \pm 0.03$ \\
\hline
\end{tabular}

$\mathrm{F} / \mathrm{P}=$ flowers per plant, $\mathrm{F} / \mathrm{S}=$ flowers per spike, $\mathrm{S} / \mathrm{P}=$ spikes per plant, $\mathrm{G} / \mathrm{P}=$ grains per plant, $\mathrm{G} / \mathrm{S}=$ grains per spike, $\mathrm{G} / \mathrm{F}=$ grains per flower.

Table 5 Two-way ANOVAs for the variables F/P, F/S, S/P, $\mathrm{G} / \mathrm{P}, \mathrm{G} / \mathrm{S}$ and $\mathrm{G} / \mathrm{F}$ in the experimental populations

\begin{tabular}{lllllll}
\hline Source of variation & $\mathrm{F} / \mathrm{P}$ & $\mathrm{F} / \mathrm{S}$ & $\mathrm{S} / \mathrm{P}$ & $\mathrm{G} / \mathrm{P}$ & $\mathrm{G} / \mathrm{S}$ & $\mathrm{G} / \mathrm{F}$ \\
\hline Paldang & & & & & & \\
$\quad$ Locality (Madrid or LC) & $\mathrm{ns}$ & $* * *$ & $\mathrm{~ns}$ & $\mathrm{~ns}$ & $*$ & $* * *$ \\
$\quad$ Number of Bs (0 or 2Bs) & $\mathrm{ns}$ & $* * *$ & $\mathrm{~ns}$ & $* * *$ & $* * *$ & $* * *$ \\
Interaction & $\mathrm{ns}$ & $\mathrm{ns}$ & $\mathrm{ns}$ & $\mathrm{ns}$ & $*$ & $*$ \\
Puyo & & & & & & \\
$\quad$ Locality (Madrid or LC) & $*$ & $* * *$ & $*$ & $* * *$ & $\mathrm{~ns}$ & $* * *$ \\
$\quad$ Number of Bs (0 or 2Bs) & $\mathrm{ns}$ & $* * *$ & $\mathrm{~ns}$ & $\mathrm{~ns}$ & $\mathrm{~ns}$ & $\mathrm{~ns}$ \\
Interaction & $\mathrm{ns}$ & $\mathrm{ns}$ & $\mathrm{ns}$ & $\mathrm{ns}$ & $\mathrm{ns}$ & $\mathrm{ns}$ \\
\hline
\end{tabular}

$\mathrm{F} / \mathrm{P}=$ flowers per plant, $\mathrm{F} / \mathrm{S}=$ flowers per spike, $\mathrm{S} / \mathrm{P}=$ spikes per plant, $\mathrm{G} / \mathrm{P}=$ grains per plant, $\mathrm{G} / \mathrm{S}=$ grains per spike, $\mathrm{G} / \mathrm{F}=$ grains per flower, $\mathrm{ns}=$ nonsignificant; *significant at 0.05 level, ${ }^{* * *}$ significant at 0.001 level.

20 per cent for plants with Bs, and the frequency of Bs in Puyo is high, of the order of about 60 per cent.

It has been observed in the synthetic populations that when the frequencies are switched there is a tendency to move towards the original natural frequencies. This tendency is especially strong in Puyo, which shows significant differences after only one generation, and reaches the original percentage of plants with Bs, and the mean number of Bs per plant, in only two generations (Tables 2 and 3). In Paldang the tendency to decrease from 60 per cent towards a lower frequency is also evident, although it is not so strong because the differences are significant only after two generations (Tables 2 and 3).

In the two localities, Madrid and La Coruna, there is a similar tendency towards the natural frequencies although this tendency is stronger in Madrid. Puyo 20 in Madrid changes from 0.22 to 0.47 plants with $\mathrm{Bs}$, so that the frequency of Bs increases by 25 per cent after only one generation, while in La Coruña it increases from 0.19 to 0.34 ; i.e. a shift of only 15 per cent. The same effect is observed for the tendency of Paldang 60 to decrease as the number of plants with Bs is reduced by 13 per cent in Madrid and 7 per cent in La Coruña.

Previous experiments with rye cultivated in different environments have shown that under conditions of increasing stress and mortality selection favours plants without Bs at the expense of plants with Bs (Rees \& Hutchinson, 1973; Teoh \& Jones, 1978). Kishikawa (1970) showed that when the temperature increases, the frequency of non-disjunction decreases, and that a decrease in soil moisture produces a higher B chromosome loss during meiosis. 
Table 6 Quotients between the mean values of $F / P, F / S, S / P, G / P, G / S$ and $G / F$ between $2 B$ and $0 B$ plants, and between $4 B$ and OB plants

\begin{tabular}{|c|c|c|c|c|c|c|c|c|c|c|c|c|}
\hline \multirow[b]{2}{*}{ Population } & \multicolumn{2}{|l|}{$\mathrm{F} / \mathrm{P}$} & \multicolumn{2}{|l|}{$\mathrm{F} / \mathrm{S}$} & \multicolumn{2}{|l|}{$\mathrm{S} / \mathrm{P}$} & \multicolumn{2}{|l|}{$\mathrm{G} / \mathrm{P}$} & \multicolumn{2}{|l|}{$\mathrm{G} / \mathrm{S}$} & \multicolumn{2}{|l|}{$\mathrm{G} / \mathrm{F}$} \\
\hline & $2 \mathrm{~B} / 0 \mathrm{~B}$ & $4 \mathrm{~B} / 0 \mathrm{~B}$ & $2 \mathrm{~B} / 0 \mathrm{~B}$ & $4 \mathrm{~B} / 0 \mathrm{~B}$ & $2 \mathrm{~B} / 0 \mathrm{~B}$ & $4 \mathrm{~B} / 0 \mathrm{~B}$ & $2 \mathrm{~B} / 0 \mathrm{~B}$ & $4 \mathrm{~B} / 0 \mathrm{~B}$ & $2 \mathrm{~B} / 0 \mathrm{~B}$ & $4 \mathrm{~B} / 0 \mathrm{~B}$ & $2 \mathrm{~B} / 0 \mathrm{~B}$ & $4 \mathrm{~B} / 0 \mathrm{~B}$ \\
\hline Paldang 20 Madrid & 0.80 & - & 0.86 & - & 0.87 & - & 0.46 & - & 0.50 & - & 0.59 & - \\
\hline Paldang 60 Madrid & 0.93 & 0.43 & 0.91 & 0.73 & 1.01 & 0.51 & 0.73 & 0.08 & 0.71 & 0.14 & 0.81 & 0.21 \\
\hline Puyo 20 Madrid & 1.10 & - & 1.02 & - & 1.13 & - & 0.89 & - & 0.88 & - & 0.86 & - \\
\hline Puyo 60 Madrid & 1.09 & 1.36 & 1.08 & 1.04 & 1.03 & 1.29 & 0.85 & 0.35 & 0.86 & 0.32 & 0.79 & 0.30 \\
\hline Paldang 60 LC & 0.93 & 1.20 & 0.99 & 0.92 & 0.93 & 1.28 & 0.68 & 0.16 & 0.72 & 0.11 & 0.74 & 0.55 \\
\hline Puyo 20 LC & 1.11 & - & 0.98 & - & 1.12 & - & 0.92 & - & 0.78 & - & 0.80 & - \\
\hline Puyo 60 LC & 1.02 & 0.62 & 0.98 & 0.86 & 1.01 & 0.70 & 0.92 & 0.13 & 0.88 & 0.18 & 0.91 & 0.21 \\
\hline
\end{tabular}

$\mathrm{F} / \mathrm{P}=$ flowers per plant, $\mathrm{F} / \mathrm{S}=$ flowers per spike, $\mathrm{S} / \mathrm{P}=$ spikes per plant, $\mathrm{G} / \mathrm{P}=$ grains per plant, $\mathrm{G} / \mathrm{S}=$ grains per spike, $\mathrm{G} / \mathrm{F}=$ grains per flower.

These previous observations cannot account for our results because we observe the same effect of a change in B frequencies in opposite directions in both environments, although the effect is stronger in Madrid than in La Coruña.

It is possible that the difference in the degree of change in B frequency observed between Madrid and La Coruña is not due to the environment, but results mainly to the way in which the synthetic populations with the switched frequencies were made for $\mathrm{La}$ Coruna. It will be recalled that they came not from the original varieties but from the Paldang 60 and Puyo 20 populations obtained in Madrid the year before. Actually the change in frequencies in 1988 and 1989 is of about the same order of magntiude both in Madrid and in La Coruña, while the main change is produced in Madrid in 1987 and 1988. We think that the factors which influence the transmission of Bs had already changed during 1987 and 1988, and the tendency to change towards the natural frequency is then much reduced.

We have also estimated variables of vigour and fertility (Table 4). The variance of the variables is always high, which decreases the sensitivity of the ANOVA. Notwithstanding questions of statistical interpretation our results are in agreement with previous data on the decrease in fertility due to Bs, and their lack of influence on vigour (Müntzing, 1963; Puertas et al., 1985; Romera et al., 1989). This effect is evident from Table 6 in which it is shown that the mean values of grains per plant, grains per spike and grains per flower are always lower in $2 \mathrm{~B}$ than in $0 \mathrm{~B}$ plants, and much lower in $4 \mathrm{~B}$ plants. On the contrary the mean values of flowers per plant, flowers per spike and spikes per plant are equal, higher or lower among plants with $0 \mathrm{~B}, 2 \mathrm{~B}$ or $4 \mathrm{~B}$.
This effect on fitness is similar in the environments in both Madrid and La Coruña because the interaction between the sources of variation due to locality and number of Bs resulted in non-significance in 10 out of the 12 cases (Table 5). A significant interaction would indicate an environmental influence on the effect of Bs on fitness. Our result is interesting because it is against an adaptive nature of $\mathrm{B}$ chromosomes in rye.

The main result of this experiment however is that both Paldang and Puyo tend to move towards their natural frequencies after they are experimentally changed. It can thus be concluded that there must be reasons which can account for the existence of $B$ chromosome polymorphisms that are determined at one particular frequency and not another. Therefore, the hypothesis that a natural population can carry Bs at a wide range of frequencies has to be rejected.

It is remarkable to observe the fast change in the frequency of plants with Bs in Puyo, which changes from the synthetic 20 per cent to its natural 60 per cent level in two generations. This indicates that the factors that maintain B chromosomes in populations are highly effective because the tendency to recover a high frequency of Bs in Puyo is stronger than the tendency to decrease from an experimentally determined high frequency in Paldang. A possible interpretation of this behaviour is that frequency-dependent selection and a maternal imprinting effect are involved in the recovery of the natural frequencies.

Frequency-dependent selection (Puertas et al., 1988 ) acts in such a way that pollen from $0 \mathrm{~B}$ or $2 \mathrm{~B}$ rye plants does not fertilize at random when these plants are at different frequencies. Pollen from 2B plants preferentially fertilizes when the proportion of $2 \mathrm{~B}$ plants is low, and pollen from $0 \mathrm{~B}$ preferentially fertilizes when the proportion of $2 \mathrm{~B}$ plants is high. If we 
consider the natural equilibrium frequency as the pivotal value from which a frequency of Bs can be regarded as high or low, the preferential fertilization would accelerate the recovery of the natural frequency.

On the other hand, the maternal imprinting effect (Puertas et al., 1990) influences the transmission of Bs through pollen. It was observed that the $\mathrm{B}$ transmission rate in $0 \mathrm{~B} \times 2 \mathrm{~B}$ crosses is much higher when the maternal parent has $2 \mathrm{~B}$ chromosomes than when it has 0B. As Paldang has a low natural frequency of plants with $\mathrm{Bs}$ (20 per cent), most plants of this population have a $0 \mathrm{~B}$ maternal parent. In Puyo, which has a high natural frequency of plants with Bs (60 per cent), many plants have a $2 \mathrm{~B}$ female parent. Therefore, the synthetic Paldang 60 tends to transmit few Bs because the plants have mainly a $0 \mathrm{~B}$ maternal parent and, similarly Puyo 20 tends to transmit many Bs because the plants have mainly a $2 \mathrm{~B}$ maternal parent.

We previously performed an experiment similar to the present work (Puertas et al. 1986, 1987) using the Japanese variety JNK, which has a high natural frequency of plants with Bs (67 per cent). From this variety we made two synthetic populations, one with a high frequency of Bs ( 80 per cent), and the other with a much lower frequency $(20$ per cent $)$. The results of this previous experiment were similar to those of the present one. The population with a high B frequency tended to lose Bs, while the population with the low frequency tended to increase its frequency quickly from 20 to about 50 per cent in only one generation, after which it seemed to remain at the new equilibrium. These results again indicate that each natural population has a tendency to keep B chromosomes at a fixed frequency, or within a narrow range of frequencies. It should be noted also that in JNK the tendency to increase the frequency of $\mathrm{B}$ chromosomes was much stronger than the tendency to decrease, again indicating the strength of the forces that maintain B chromosomes in populations in spite of their adverse effects on fertility.

We have already demonstrated (Romera et al., $1989)$ that the non-Mendelian accumulation mechanisms of B chromosomes, and their harmful effect on fertility, cannot account for the establishment of equilibria at different frequencies in different populations. In our opinion, the genes that control the transmission rate of B chromosomes (Romera et al., 1991) are the main factors that determine the range of frequencies at which a population can carry Bs in nature. If the allele or alleles causing a high transmission rate of $\mathrm{B}$ chromosomes are at a high frequency in a population, the population will have a natural high frequency of B chromosomes, and, conversely, if the alleles causing a low transmission rate of $\mathrm{Bs}$ are at a high fre- quency, the population will have a low natural B frequency.

A question which now arises is, how is it that the genes that produce a high transmission rate of $\mathrm{B}$ chromosomes can be present at a high frequency in a natural population, as the plants with Bs show low fertility. This question needs further investigation because we still do not have sufficient knowledge about the mode of action of the genes that affect the transmission rate of $\mathrm{B}$ chromosomes in rye.

\section{Acknowledgements}

This work was supported by the grant PB 88-0122 from the DGICYT of Spain.

\section{References}

KISHIKAWA, H. 1965. Cytogenetic studies of B chromosomes in rye, Secale cereale in Japan. Agr. Bul. Saga Univ., 21, $1-81$.

KISHIKAWA, H. 1970. Effects of temperature and soil moisture on frequency of accessory chromosomes in rye, Secale cereale L. Jap. J. Breeding, 20, 269-274.

JONES, R. N. AND REES, H. 1982. B chromosomes. Academic Press, London.

LEE, W. J. 1963. Frequency and geographical distribution of rye (Secale cereale) with accessory chromosomes in Korea. Preliminary report. Kor. J. Bot., 6, 15-17.

LEE, w. J. 1966. On accessory chromosomes in Secale cereale III. Relationship between the frequency of accessory chromosomes in rye and soil properties. Kor. J. Bot., 9, 33-38.

LEE, W. J. 1976. Frequency of rye (Secale cereale) with B chromosomes in Yechon Area. Kor. J. Breeding, 8, 153-155.

LEE, w. J. 1981. Frequency of B chromosomes in rye (Secale cereale) cultivated in Paldang. Kor. J. Bot., 24, 181-190.

LEE, w. J. AND MIN, B. R. 1965. On accessory chromosomes in Secale cereale I. Frequency and geographical distribution of plants with accessory chromosomes in Korea. Kor. $J$. Bot., 8, 41-46.

LEE, W. J. AND MIN, B. R. 1966. Frequency and geographical distribution of rye with accessory chromosomes in Korea. Wheat Inf. Ser., 21, 27-29.

LEE, W. J. AND MIN, B. R. 1968. On accessory chromosomes in Secale cereale. IV Further study on frequency and geographical distribution of rye with accessory chromosomes in Korea. Kor. J. Bot., 11, 71-75.

MUNTZING, A. 1954. Cytogenetics of accessory chromosomes (B-chromosomes) Caryologia, (Vol. Suppl. 6), 282-301.

MÚNTZING, A. 1957a. Frequency of accessory chromosomes in rye strains from Iran and Korea. Hereditas, 43, 682-685.

MÜNTZING, A. 1957b. Frequency of accessory chromosomes in rye from Korea. Wheat Inf. Ser., 5, 16-18. 
MÜNZING, A. 1963. Effects of accessory chromosomes in diploid and tetraploid rye. Hereditas, 49, 361-426.

PUERTAS, M. J., BAEZA, F. AND DE LA PENA, A. 1986. The transmission of $\mathrm{B}$ chromosomes in populations of Secale cereale and Secale vavilovii 1 . Offspring obtained from $0 \mathrm{~B}$ and $2 \mathrm{~B}$ plants. Heredity, 57, 389-394.

PUERTAS, M. J., JIMENEZ, M. M., ROMERA, F, VEGA, J. M. AND DIEZ, M. 1990. Maternal imprinting effect on B chromosome transmission in rye. Heredity, 64, 197-204.

PUERTAS, M. J., RAMIREZ, A. AND BAEZA, F. 1987. The transmission of $\mathrm{B}$ chromosomes in Secale cereale and Secale vavilovii populations II. Dynamics of populations. Heredity, 58, 81-85.

PUERTAS, M. J., ROMERA, F. AND DE LA PEÑA, A. 1985. Comparison of B chromosome effects on Secale cereale and Secale vavilovii. Heredity, 55, 229-234.
PUERTAS, M. J., VEGA, J. M., ROMERA, F. AND DIEZ, M. 1988. Frequency dependent fertilisation involving rye $B$ chromosomes. Heredity, 61, 143-147.

REES, H. AND HUTCHINSON, J. 1973. Nuclear DNA variation due to B chromosomes. Cold Spring Harb. Symp. Quant. Biol., 38, 175-182.

ROMERA, F., JIMENEZ, M. M. AND PUERTAS, M. J. 1991. Genetic control of the rate of transmission of rye $\mathrm{B}$ chromosomes $\mathrm{I}$. Effects in $2 \mathrm{~B} \times 0 \mathrm{~B}$ crosses. Heredity, 66, 61-66.

ROMERA, F., VEGA, J. M., DIEZ, M. AND PUERTAS, M. J. 1989. B chromosome polymorphism in Korean rye populations. Heredity, 62, 117-121.

TEOH, S. B. AND JONES, R. N. 1978. B chromosome selection and fitness in rye. Heredity, 41, 35-48. 